\title{
The Determinants of Defense Expenditure in China's Peaceful Rise
}

\author{
Lixiang Chen ${ }^{1,2}$
}

\author{
${ }^{1}$ Institute of Finance and Economics, Central University of Finance and Economics, Beijing, China; \\ ${ }^{2}$ Department of Economics and Management, Taiyuan Institute of Technology, Taiyuan, China
}

Received: 23 Nov 2020; Received in revised form: 16 Dec 2020; Accepted: 22 Dec 2020; Available online: 27 Dec 2020

C 2020 The Author(s). Published by Infogain Publication. This is an open access article under the CC BY license

(https://creativecommons.org/licenses/by/4.0/).

\begin{abstract}
The determinants of defense expenditure demand are mainly military activities, economic factors, political environment, and other related factors. Based on this, this paper analyzes and tests the characteristics of China's defense expenditure demand from 1952 to 2016.The empirical analysis is based on the autoregressive distributed lag model-Bound Test, to analyze the long-term co-integration relationship between defense expenditure demand and its determinants. Meanwhile, the results show that the long-term elasticity of China's defense expenditure demand is higher than the short-term elasticity.

Keywords-defense expenditure demand, autoregressive distributed lag model, bounded co-integration test.
\end{abstract}

\section{INTRODUCTION}

Since the end of 1990s, China's defense expenditure has been in a relatively rapid growth period. According to Chinese official data, China's defense expenditure has maintained double-digit growth in recent years. Officials and researchers in many western countries believe that China's actual defense expenditure is far greater than the officially announced data, and point out that China's officially announced defense expenditure only accounts for a part of its total defense expenditure in SIPRI Yearbook (2004). China's defense budget in 2016 (the plan for the two sessions) is 954.354 billion yuan (about 104.354 billion U.S. dollars), and China's defense expenditure in 2016 announced by the internationally renowned research institute SIPRI is 215.176 billion U.S. dollars (about $1,463.111$ billion yuan). This can be explained by different statistical calibers and different definitions of defense expenditure. At the same time, with the rapid development of China's economy since the reform and opening, China's international influence has increased rapidly, and China's role in the development of the world economy has become increasingly important. Therefore, the growth of China's defense expenditure has also triggered the rise of the "China threat theory". 


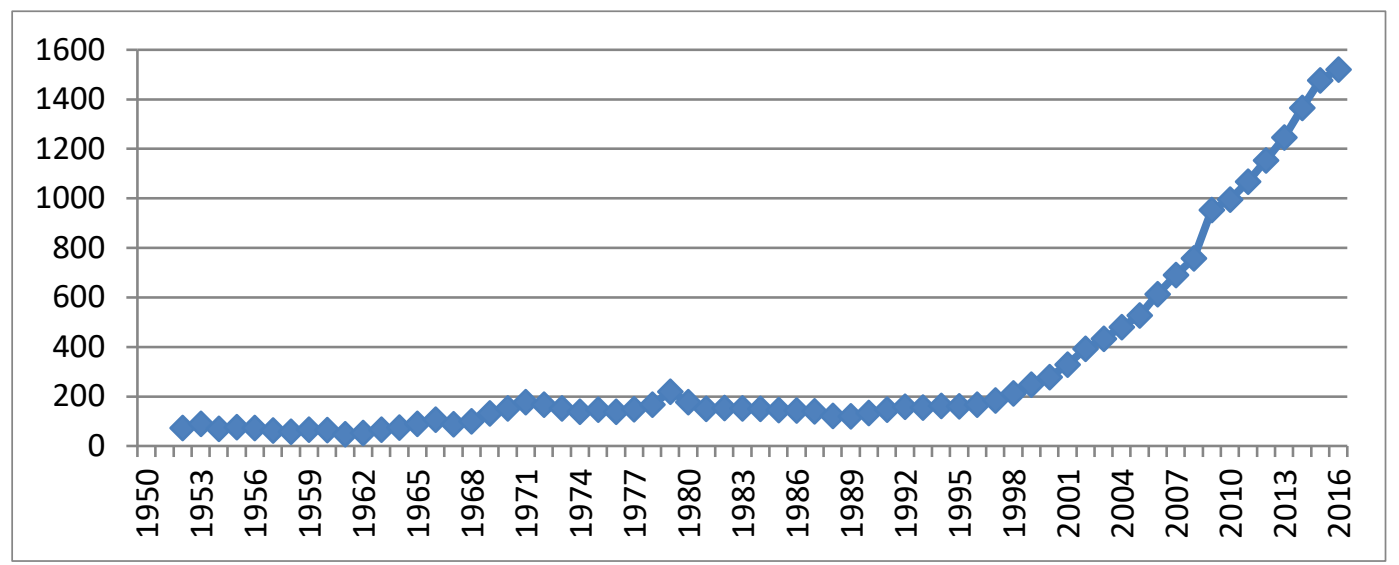

Fig.1: Actual value of defense expenditure (100 million RMByuan)

China's defense expenditure was at a relatively low level at the beginning of the founding of the People's Republic of China in 1949. Before the 1980s, China's defense expenditure fluctuated frequently due to the contradiction between consolidating the new regime and building the country. China's defense expenditure fluctuated frequently, which was determined by the external environment. Fig. 1 shows the trend of the actual value of China's defense expenditure, and Fig.2 shows that China's defense burden has been declining and tending to stabilize.

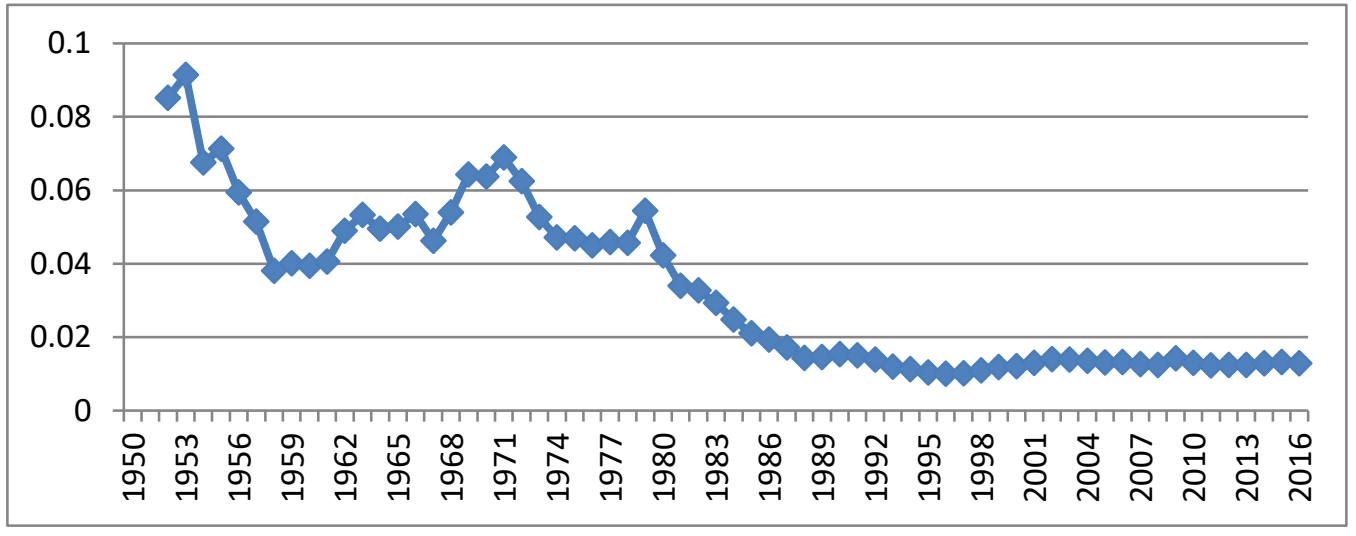

Fig.2.: National defense burden (\%)

According to China's official data, between 1952 and 1978, the highest proportion of China's defense expenditure to GDP was 9.14\% (1953), and the lowest was $3.81 \%$ (1958). After 1979, in order to support the country's economic construction, defense expenditures were in a period of relative contraction, making China's defense expenditures at a relatively low level during this period. From 1979 to 2008, the highest proportion of national defense expenditure in fiscal expenditure was $17.39 \%$ (1979), and the lowest was 6.68\% (2008); the highest proportion of national defense expenditure to GDP from
1979 to 2008 was $5.44 \%$ (1979), and the lowest was $1.01 \%$ (1996). This period can be divided into three stages. In the first stage, from 1979 to 1987 , China's defense construction was in a state of low investment and maintenance. The defense expenditure increased by an average of $3.5 \%$ per year. In the same period, GDP grew by an average of $14.1 \%$ per year at current prices, the national fiscal expenditure increased by an average of $10.4 \%$ annually. The proportion of defense expenditure in GDP and national fiscal expenditure dropped from $4.6 \%$ and $14.96 \%$ in 1978 to $1.74 \%$ and $9.27 \%$ in 1987 . In the 
second phase, from 1988 to 1997 , in order to make up for the lack of national defense infrastructure and maintain national security and unity, China gradually increased its defense investment based on its continuous economic growth. The average annual growth rate of defense expenditure was $14.5 \%$. In the same period, GDP grew by an average of $20.7 \%$ per year at the current price. The average annual growth rate of national fiscal expenditure increased by $15.1 \%$. The proportion of defense expenditure in GDP and national fiscal expenditure continued to decline. In the third phase, from 1998 to 2008, in order to maintain national security and development interests and meet the needs of military reform with Chinese characteristics, China continued to maintain a steady increase in defense expenditures based on rapid economic growth. Defense spending increased by an average of $15.9 \%$ per year. During the same period, GDP increased by $12.5 \%$ at the current price, and national fiscal expenditure increased by $18.4 \%$. From 2008 to 2016 , the scale of defense expenditure levels continued to grow steadily, but the average annual growth rate of defense expenditure dropped to $9.2 \%$, which is consistent with the slowdown in economic growth during the same period.

As can be seen from the development process of China's national defense expenditure, the scale of national defense expenditure is constantly rising, but the burden of national defense has been kept at a low level, and the proportion of national defense expenditure in fiscal expenditure has been gradually decreasing. What determines China's defense spending needs? This paper introduces from several parts, first introduces the research status of the determinants of national defense expenditure demand at home and abroad, to understand that many factors that affect national defense expenditure have different influences on different countries. The general experience is to establish the empirical model of national defense expenditure demand decision, and analyze and expand on this basis. The second part introduces the general influencing factors, the third part constructs the theoretical model, and the fourth part makes empirical analysis. The fifth part gives the empirical results.

\section{FACTORS INFLUENCING DEFENSE EXPENDITURE DEMAND}

General research on defense expenditure demand can be divided into transnational regression model and time series analysis based on single country according to different research countries. The factors that determine the demand for defense expenditure are also divided into several categories: military activities, economic factors, political environment, and other related factors.

According to foreign scholars, Gadea et al. (2004) analyzed the influencing factors of long-term (1960-1999) defense expenditure demand by homogenizing the 15 NATO member States. Including income, external threats, and allied spending. The threat of civil war also has a very significant impact on the security of developing countries. Paul pointed out that the threat of civil war exceeded the external threat, Collier \&Hoeffler (1998) measured the internal threat by estimating the possibility of civil war, and had similar results. Dunne, Perlo Freeman, \& Smith (2008) also pointed out that civil war played an important role in the demand of defense expenditure.

The overall economic environment has a long-term basic constraint on national defense expenditure. Looney \& Mehay (1989) pointed out that internal economic factors such as economic development level, actual economic growth, government budget and the interaction between defense and industrial complex are all very important influencing factors of defense expenditure demand. National income is widely regarded as the most important factor. In terms of international economic impact, Maizels \& Nissanke (1987)believe that the increase of foreign exchange reserves, foreign capital and international military assistance are important factors affecting the demand for defense expenditure. Dunne, Smith, \& Willenbockel (2005) research uses trade volume (total import and export) to measure the impact of economic openness on defense expenditure demand. The results show that the total trade volume has a significant positive impact on the defense expenditure demand of developing countries.

In terms of political factors, the type of government and political stability are also important factors for the defense expenditure demand of developing countries. 
West believes that the most important factor of defense expenditure demand is the interaction between domestic bureaucracy and politics. Harris also believes that the relative capabilities and spheres of influence of military blocs will affect defense expenditure and distribution. In addition to being affected by political stability, changes in policy, especially in defense policy, also affect a country's defense expenditure.

Population variable is widely used in the demand equation of defense expenditure. This variable may be regarded as a default security factor, which can reduce the demand of defense expenditure. In addition, the theory of public goods holds that as a pure public goods, improving security benefits to more people will make defense expenditure more efficient.

Among other factors, regional factors are used to reflect the influence of "bad neighbor relationship" and "contagion" on the demand of defense expenditure. Last year's defense spending is also one of the best indicators of current defense spending. In the empirical analysis, the lag variable of defense expenditure is added to the most explanatory variable.

Many domestic scholars have focused on the relationship between China's defense expenditure and economic growth, while few have studied the influencing factors of defense expenditure demand. By analyzing the determinants of defense expenditure, Lu Zhoulai found that China's defense expenditure is related to national income, military expenditure of threatening party or potential threatening party. Sun \& Yu (1999) used the American Arms Control and Sanctions Agency (ACDA) and Chinese official data to study China's defense expenditure demand from 1965 to 1993, showing that China's defense expenditure was affected by national income, threatening national and regional defense expenditure and time lag variables, while the reform and opening-up policy in 1979 had a negative impact on China's defense expenditure. However, the border conflict has no significant impact on China's defense expenditure demand. Bing-Fu \& Liming (2006)analyzed the determinants of national defense expenditure before and after China's transformation (reform and opening), and analyzed the changes of determinants of national defense expenditure demand in two sub-stages
(1960-1980,1981-1999). It was found that the dominant factors of national defense expenditure demand changed in different stages, from security threats in the early stage to economic factors in the later stage.

The demand for defense expenditure in a single country is based on time series analysis, and can be empirically analyzed by using the unique military, economic, political, and other factors of the country. In the empirical analysis method, the autoregressive distributed lag model ARDL and Solomon (2005) are used to analyze the determinants of Canada's defense expenditure demand from 1952 to 2001. The ARDL model is used to estimate and test the cointegration and long-term relationship between defense expenditure and its determinants. Nikolaidou (2008) analyzed the decisive factors of the defense expenditure demand of the $15 \mathrm{EU}$ countries from 1961 to 2015, built the ARDL model and tested each country separately, and found significant common factors and individual factors that determined the defense demand. Abdelfattah, Abu-Qarn, Dunne, \& Zaher (2014)used the dynamic model to analyze the cointegration relationship between Egyptian defense expenditure demand and determinants, and used the test of endogenous structural breakpoints when estimating the cointegration relationship. The long-term cointegration with time breakpoints is more significant than the general cointegration method. Domestic scholars Jiang Yiwen and Luo Min (2005) used autoregressive distributed lag model to estimate the determinants of China's defense expenditure demand (1978-2003), and found that the long-term elasticity and short-term elasticity of China's defense expenditure demand are both inelastic.

Based on the previous analysis, the decisive factors of defense expenditure demand in a single country or across countries are generally considered from military, political and economic aspects, but the analysis of a single country should also consider the differences of special factors in combination with the actual situation in China. This paper also focuses on the time series analysis of national defense expenditure of a single country, and the decisive factors are mainly economic factors and external threats. In terms of political stability, China's political stability has been generally stable since the founding of the 
People's Republic of China, and its national defense policy has always been based on non-alignment and active defense, which can be expected to have little impact on China's national defense expenditure. In addition, in the method of empirical analysis, combined with the characteristics of defense expenditure budget system, this paper also uses autoregressive distributed lag model, namely ARDL model, to analyze the long-term cointegration relationship between defense expenditure demand and determinants. In the co-integration test method, the usual E-G two-step method and Johansen test are not used, but the boundtest co-integration test, which was put forward and applied by Pesaran, Shin, \& Smith (2001), has been recognized in the mainstream economic fields abroad. However, there are not many achievements applied to the field of national defense economy in China, but it is more appropriate to use this method to analyze the decision of national defense expenditure demand, or to analyze the long-term and short-term impact of national defense expenditure demand.

\section{THEORETICAL FRAMEWORK OF DEFENSE EXPENDITURE DEMAND}

There are two theoretical models for studying the decision of defense expenditure: one is Richardson's arms race model; The other is based on neoclassical model, integrating economic, political, and strategic factors, and using comparative analysis. Richardson's model is suitable for countries in conflict, and the empirical results can't explain the reality well. At present, some studies have integrated these two methods, introducing the dynamic arms race into the demand model, using a more complex structural model instead of the action response framework, and comprehensively considering economic, political, and military factors.

The model adopt in this paper is based on that neo-classical demand model established by Smith (1980, $1987,1995)$, assuming that social welfare is a function of civil output and safety. Defense expenditure is one of the factors that determine security. The government's function is to balance the security utility brought by increasing national defense expenditure and the opportunity cost of national defense expenditure (reduction of civil output) in order to maximize social welfare. Therefore, social welfare ISSN: 2456-7620 w can be expressed as a function of safety $\mathrm{s}$ and total consumption c of economic variables.

Social welfare function:

$$
\mathrm{W}=\mathrm{W}(\mathrm{S}, \mathrm{C})(1)
$$

The national budget constraint is expressed as:

$Y_{t}=P_{C_{t}} C_{t}+P_{m_{t}} M_{t}(2)$

$\mathrm{Y}$ is nominal gross income, $\mathrm{P}_{\mathrm{m}}$ and $\mathrm{P}_{\mathrm{c}}$ represent actual defense expenditure and consumption price respectively.

Security is also an unobservable and difficult variable to quantify. Generally, it is expressed by substitution variables, such as the military strength $M$ of our country, the military strength $\mathrm{M}_{\mathrm{i}}$ of other countries and the strategic variable $\mathrm{Z}$. Therefore, the safety function is expressed as:

$$
\mathrm{S}=\mathrm{S}\left(M, M_{i}, \mathrm{Z}\right)(3)
$$

In general, security depends on the stock of military forces rather than the flow-defense expenditure. Military strength stock includes military equipment and human capital, which can be defined as the sum of historical defense expenditures after depreciation.

$$
K_{t}=M_{t}+(1-\delta) K_{t-1}(4)
$$

Here, $\delta$ stands for depreciation rate, representing the current national defense capital stock, and 1 represents the past national defense capital stock. In this way, the equation (1)-(4) can be expressed by the demand function of defense expenditure.

$$
M t=M(P m t, P c t, Y t, K t-1, K 1 t, Z)
$$

The general dynamic formula of defense expenditure demand can be expressed as:

$$
\text { Mt }=\beta 0 \delta+\beta 1 \mathrm{yt}-\beta 1(1-\delta) \mathrm{yt}-1+(\beta 2+
$$$$
(1-\delta)) \mathrm{Mt}-1+\beta 3 \mathrm{M} 1 \mathrm{t}+\beta 4 \mathrm{Z} \quad \text { (6) }
$$

Of course, specific forms can be considered for studying different factors of a single country.

\section{EMPIRICAL ANALYSIS}

In order to facilitate the research, the model of empirical test is defined as a general dynamic model, and the function form is: 


$$
\text { mil }=\mathrm{F}\left(\mathrm{Y}, \sum_{i} \text { mil }, p o p, z\right)
$$

In equation (7) mil represents the actual value of China's defense expenditure (1978 price index as the base period), Y represents the actual value of GDP (1978 price index as the base period), $\sum$ represents the actual value of defense expenditure of other countries, mainly considering external threats and neighboring countries, mainly the United States, Japan, India, Russia, and Taiwan. POP is a logarithmic form representing the total population, and $\mathrm{z}$ represents other political or threat variables. Other countries' defense expenditure data comes from SIPRI2016, which is the yearbook data of Stockholm Peace Research
Institute. Russia's data is only from 1992 to 2015, and Taiwan's data is also from 1976 to 2015 . Therefore, in the process of model estimation, due to the lack of complete data, the full sample analysis of these two parts of data was not carried out. The data of other countries are all in US dollars, which are not converted into RMB by exchange rate, but in logarithmic form to eliminate dimensional differences. The data of China's defense expenditure comes from the data of China Statistical Yearbook and Ministry of Finance, covering the period from 1952 to 2016. Specific variable selection and description are shown in the following table.

Table 1. Variable Description and Data Source

\begin{tabular}{ccc}
\hline $\begin{array}{c}\text { Variable } \\
\text { name }\end{array}$ & Meaning & Source \\
\hline lnmilitray & Logarithmic form of China's defense expenditure & Ministry of finance \\
lngdp & Logarithm of China's GDP & statistical bureau \\
lnpop & Logarithmic form of China's total population & statistical bureau \\
lnUSA & Logarithmic form of US defense expenditure & SIPRI \\
lnRUSSIA & Logarithmic form of Russia defense expenditure & SIPRI \\
lnJAPAN & Logarithmic form of Japan defense expenditure & SIPRI \\
lnINDIA & Logarithmic form of India defense expenditure & SIPRI \\
$Z$ & For polity, other virtual variables, such as time & \\
\hline
\end{tabular}

In this paper, the autoregressive distributed lag model (ARDL) developed by Pesaran and Shin(1999) is adopted. The advantage of this method is to analyze the long-term cointegration relationship between variables, and if the lag order of ARDL model is determined, the estimated values of long-term parameters and short-term parameters can be obtained by using the least square method, and reasonable gradual inference can be obtained, which is impossible for other cointegration methods. Cointegration method is also a bounded cointegration test proposed by Pesaran et al. (2001). The commonly used EG two-step method and Johansen test method have a problem corresponding to China's data test, that is, the small sample problem, the time span is small, the test value will be biased, the cointegration relationship may be unreliable, and the analysis results lack robustness 。There are two methods to solve this problem in the previous literature: one is to use quarterly or monthly data to artificially increase the sample size, but this practice has been questioned. Hakkio\& Rush (1991) found that using quarterly or monthly data to increase the sample size cannot increase the robustness of cointegration test, which mainly depends on the time span rather than the number of observed values; Another method is to extend the time span and include the data before 1980s, but this is based on the theoretical model of market economy to analyze the behavior under the condition of planned economy, and the methodology itself has problems. Bounded method also has a good characteristic, that is, it can be used regardless of the stationarity of regression variables, that is, whether the regression variables are horizontally stationary or first-order unitary. In contrast, Johansen method and EG method can only be used to 
analyze non-stationary variables with the same unitary order ( $\mathrm{I}(1)$ ), which requires the unit root test of variables first, and in this process, subjectivity and uncertainty will inevitably be introduced to a certain extent. Therefore, this paper also tests based on ARDL-ECM model combined with bounded cointegration test method.

At first, the self-regressive distribution lag mode and error correction mode, ARDL(p,q),ECM(i) are given, and the key is to determine the lag order. Generally, AIC and SC criteria are used for selection.

The ARDL model can be expressed as:

Dlnmility $_{t}=\beta_{0}+\sum_{i=0}^{k} \beta_{1 i} D \operatorname{Dlng} d p_{t-i_{1 i}}+$ $\sum_{i=0}^{k} \beta_{2 i}$ Dlnpop $_{t-i}+\sum_{i=1}^{k} \beta_{3 i}$ Dlnmilty $_{t-i}+$ $\sum_{i=0}^{k} \beta_{4 i}$ Dlnusa $_{t-i}+\sum_{i=0}^{k} \beta_{5 i}$ Dlnjapan $_{t-i}+$ $\sum_{i=0}^{k} \beta_{6 i}$ Dlnindia $_{t-i}+\lambda \mathrm{ECM}_{t-1}+\mu_{t}$

$\mathrm{D}$ in the above equation (8) represents the difference term, in which ECM is the error correction term. ARDL model also analyzes the long-term relationship and short-term relationship between variables. The coefficient of the difference term indicates the short-term relationship coefficient or short-term elasticity, while the error correction term (9) indicates the adjustment of the long-term equilibrium relationship, and the coefficient $\lambda$ is the error adjustment parameter, indicating the adjustment range of the long-term equilibrium relationship. Coefficient is the long-term elastic coefficient.

Then bounded cointegration test is Wald joint test ( $F$ test) for lag variables in error correction model. The specific original hypothesis is $\alpha_{1}=\alpha_{2}=\alpha_{3}=\alpha_{4}=\alpha_{5}=0$, If the original hypothesis holds, there is no cointegration relationship among variables; otherwise, the alternative hypothesis holds, which indicates that there is cointegration relationship among variables.

\section{EMPIRICAL RESULTS}

The empirical results of the specific model are realized by Eviews9.0. The estimation method of software version 9.0 added ARDL model is more convenient to calculate. By comparing ARDL models with different lag orders, it is found that ARDL $(2,2,2)$ is the second-order lag variable of explanatory variables including LNGDP, LNPOP, and the second-order lag variable of explained variable LNMILITY, and the regression parameters are significant except constant terms. This shows that China's defense expenditure is significantly affected by income, population, and the level of past defense expenditure, but the bounded test has a significant result at $10 \%$ there is a long-term cointegration relationship at $10 \%$. However, this model does not consider the external factors affecting defense expenditure and the expenditure scale of other countries. Therefore, this model $\operatorname{ARDL}(3,4,4,1,1,2)$ is a model with the defense expenditure variables of the United States, India, and Japan. Most of the parameter results are still significant, but some parameters become insignificant, and the maximum lag term also increases. As to the variables of income, LNGDP is significant only when it lags the first period, while the parameters of the current level of expenditure in the United States are not significant, while the current and 10 periods of Indian defense expenditure are not significant. Then the bounded cointegration test results are significant at $1 \%$ level. It shows that after adding external threat factors, the results are relatively in line with expectations, but some parameters are not significant. Finally, after adjusting the external factors, only the influence of the US and Japan's defense expenditure factors is retained, and the result is also significantly improved after removing the Indian factor. That is to say, the model parameter $\operatorname{ARDL}(4,1,2,1,1)$ is more remarkable. Of course, we should also consider other virtual variables, such as major political and military events $(1962,1969,1979.1997)$. Adding time virtual variables will make the model parameters change little, and the parameters of virtual variables themselves are not significant. Adjustment of other control variables, such as polity, cannot improve the model results, so the model $\operatorname{ARDL}(4,1,2,1,1)$ is finally determined, and the results of bounded test are shown in the following Table.2. 
Table.2 Bounded cointegration test

\begin{tabular}{ccc}
\hline $\operatorname{ARDL}(2,2,2)$ & $\operatorname{ARDL}(4,1,2,1,1)$ & $\operatorname{ARDL}(3,4,4,1,1,2)$ \\
\hline $\mathrm{F}$ & $\mathrm{F}$ & $\mathrm{F}$ \\
$\mathrm{k}=2$ & $\mathrm{k}=4$ & $\mathrm{k}=5$ \\
$4.332913^{*}$ & $10.76084 * * *$ & $5.826012 * * *$ \\
$\mathrm{I}(0)$ & & \\
\hline
\end{tabular}

* The result is significant at $10 \%$ significance level,

$* * *$ the result is significant at $1 \%$ level, and $\mathrm{K}$ is the biggest lag term

Finally, the autoregressive distributed lag model is $\operatorname{ARDL}(4,1,2,1,1)$, in which the insignificant lag variables are removed, and the regression equation and error correction model of long-term relationship are given in Table.3. A series of robustness tests, such as sequence correlation LM test, conditional heteroscedasticity test

\begin{abstract}
$\mathrm{ARCH}$ and normal distribution test, were carried out on the long- term equilibrium relationship model. It was found that the results were all in line with expectations, and there was no sequence correlation and heteroscedasticity, and they obeyed normal distribution.
\end{abstract}

Table.3 Long-term cointegration equation and error correction equation results

\begin{tabular}{|c|c|c|c|c|c|c|c|c|c|}
\hline \multicolumn{5}{|c|}{ Cointegrating Form: ECM-ARDL dependent variable DLNMITY } & \multicolumn{5}{|c|}{ Long Run Coefficients: ARDL $(4,1,2,1,1)$} \\
\hline Variable & Coefficient & $\begin{array}{l}\text { Std. } \\
\text { Error }\end{array}$ & t-Statistic & Prob. & Variable & Coefficient & $\begin{array}{l}\text { Std. } \\
\text { Error }\end{array}$ & t-Statistic & Prob. \\
\hline D(LNMITY(-1)) & 0.319106 & 0.103869 & 3.072207 & 0.0036 & LGDP & -1.963677 & 0.676615 & 2.902208 & 0.0057 \\
\hline D(LNMITY(-2)) & -0.14225 & 0.039379 & -3.612376 & 0.0007 & LNPOP & 2.623775 & 0.672307 & 3.902642 & 0.0003 \\
\hline D(LNMITY(-3)) & -0.07704 & 0.040594 & -1.897808 & 0.064 & LNJAPAN & 0.904326 & 0.366715 & 2.466015 & 0.0175 \\
\hline $\mathrm{D}(\mathrm{LGDP})$ & 0.068841 & 0.067681 & 1.017138 & 0.3144 & LNUSA & -0.371042 & 0.581562 & -0.63801 & 0.5266 \\
\hline D(LNPOP) & 0.974271 & 0.052379 & 18.600471 & 0 & $\mathrm{C}$ & 8.926942 & 8.270024 & 1.079434 & 0.286 \\
\hline D(LNPOP(-1)) & -0.46618 & 0.112464 & -4.145155 & 0.0001 & & & & & \\
\hline D(LNJAPAN) & 0.758321 & 0.17729 & 4.277303 & 0.0001 & & & & & \\
\hline D(LNUSA) & 0.161534 & 0.074846 & 2.158201 & 0.0362 & & & & & \\
\hline $\operatorname{ECM}(-1)$ & -0.07744 & 0.027486 & -2.817537 & 0.0071 & & & & & \\
\hline \multicolumn{9}{|c|}{ ECM $=$ LNMITY $-(-1.9637 *$ LGDP + 2.6238*LNPOP + 0.9043*LNJAPAN } & \\
\hline
\end{tabular}

From the results, the long-term elasticity of LNMITY about LNGDP is 1.9637 , and the sign is negative; The long-term elasticity of LNMITY is 2.62 for LNPOP, 0.9 for Japanese defense expenditure, and 0.37 for American defense expenditure, which is also negative. The short-term elasticity of LNM is 0.069 for LNGDP, 0.97 for
LNPOP, 0.75 for Japanese defense expenditure and 0.16 for US defense expenditure. The long-term elasticity of China's defense expenditure to domestic economic factors is greater than the short-term elasticity, and the response to external threats, that is, the long-term and short-term elasticity of defense expenditure of other countries is not large. At the 
same time, the adjustment size of error correction of long-term equilibrium relationship is 0.07 , which is not very large. This is a high-order autoregressive feature of the performance of China's defense expenditure, which also shows that it is influenced by the base rolling budget system of defense expenditure. Overall, the decisive factor of China's national defense expenditure is mainly influenced by domestic economic factors, and of course, external threats must also be taken seriously. Of course, the empirical results are also questionable. Here, the time trends and breakpoints have not been eliminated. When Chen Bingfu (2006) analyzed the changes of defense expenditure before and after the reform and opening, the defense expenditure was mainly affected by external threats before the reform, and then mainly by the economic factor. In this paper, we try to consider the breakpoints in long-term cointegration, such as 1979 and 1997, but the results are not obviously improved. Perhaps the data sources and processing, sample size are related, and other control variables are considered. This is also worthy of further study and discussion.

\section{REFERENCES}

[1] Abdelfattah, Y. M., Abu-Qarn, A. S., Dunne, J. P., \& Zaher, S. (2014). The demand for military spending in Egypt. Defence and Peace Economics, 25(3), 231-245

[2] Bing-Fu, C., \& Liming, Z. (2006). The determinants of China's defense expenditure before and after transition. Conflict Management and Peace Science, 23(3), 227-244

[3] Collier, P., \&Hoeffler, A. (1998). On economic causes of civil war. Oxford economic papers, 50(4), 563-573

[4] Dunne, J. P., Perlo Freeman, S., \& Smith, R. P. (2008). The demand for military expenditure in developing countries: hostility versus capability. Defence and Peace Economics, 19(4), 293-302

[5] Dunne, J. P., Smith, R. P., \&Willenbockel, D. (2005). Models of military expenditure and growth: A critical review. Defence and peace economics, 16(6), 449-461

[6] Gadea, J., Sellés, E., Marco, M. A., Coy, P., Matás, C., Romar, R.,... Ruiz, S. (2004). Decrease in glutathione content in boar sperm after cryopreservation: Effect of the addition of reduced glutathione to the freezing and thawing extenders. Theriogenology, 62(3-4), 690-701
[7] Hakkio, C. S., \& Rush, M. (1991). Cointegration: how short is the long run? Journal of international Money and Finance, 10(4), 571-581

[8] Looney, R. E., \&Mehay, S. (1989). Causal factors in United States postwar defense spending: The empirical dimension. Defense Analysis, 5(2), 155-157

[9] Maizels, A., \&Nissanke, M. K. (1987). The causes of military expenditure in developing countries. Deger, S. et West, R.(dir. pub.) Defence, Security and Development, Frances Pinter, 129-139

[10] Nikolaidou, E. (2008). The demand for military expenditure: Evidence from the EU15 (1961-2005). Defence and Peace Economics, 19(4), 273-292

[11] Pesaran, M. H., Shin, Y., \& Smith, R. J. (2001). Bounds testing approaches to the analysis of level relationships. Journal of applied econometrics, 16(3), 289-326

[12] Solomon, S. M. (2005). Spatial and temporal variability of shoreline change in the Beaufort-Mackenzie region, Northwest Territories, Canada. Geo-Marine Letters, 25(2-3), 127-137

[13] Sun, Q., \& Yu, Q. (1999). Determinants of China's military expenditures: 1965-93. Journal of Peace Research, 36(1), 23-33

[14] Yearbook, S. (2004). Stockholm International Peace Research Institute. Armaments Disarmament and International Security, various years. 